Running head: EMBEDDED ANIMATIONS AND ONLINE DISCUSSION

\title{
Effect of an Animated Classroom Story Embedded in Online Discussion on Helping Mathematics Teachers Learn to Notice
}

Vu Minh Chieu and Patricio Herbst

School of Education, University of Michigan,

610 East University Ave., Ann Arbor, MI 48109

Michael Weiss

Department of Teacher Development and Educational Studies, Oakland University, 470E Pawley Hall, Rochester, MI 48309

Contact Author: Patricio Herbst

Telephone number: 734-763-3745

Email: pgherbst@umich.edu 
Running head: EMBEDDED ANIMATIONS AND ONLINE DISCUSSION. Accepted for publication at the Journal of the Learning Sciences

\begin{abstract}
Rich-media representations of teaching using animated cartoons can be effective to stimulate teachers' discussion about practice, and hence help them learn productively from each other about their profession. Our research aims to design web-based interactive rich-media virtual settings for teachers to learn to do the practice of teaching. For that purpose, we seek a set of operational design principles that could be used to optimally exploit web-based interactive rich-media technologies. By operational design principles, we mean guidelines that facilitate decision-making in the creation of learning conditions. In this paper, we report on a study of the effect of embedded animated clips of instructional practice in online interactive forum/chat to support teachers in learning to notice and interpret critical events of classroom interactions. The study shows that both novice and experienced teachers actively participated in discussion and effectively noticed important events of teaching practice. The main findings include: (a) embedding animated representations of teaching in forum/chat, by serving as a common point of reference, helps both novice and experienced teachers effectively notice and discuss noteworthy events in teaching practice; (b) forum suits novice teachers better than chat, and (c) both forum and chat suit experienced teachers in different ways. This study is a critical step in a design-based research agenda toward the building of more complex virtual settings for teacher education.
\end{abstract}


Running head: EMBEDDED ANIMATIONS AND ONLINE DISCUSSION. Accepted for publication at the Journal of the Learning Sciences

\section{Effect of an Animated Classroom Story Embedded in Online Discussion on Helping Mathematics Teachers Learn to Notice}

Practice is essential, even indispensable, for the development of many professions, including jazz improvisation in music (King, 2001), surgery (Chieu, Luengo, Vadcard, \& Tonetti, in press), health care (Bren, 2005), teaching (Lampert, 2010; Shavelson, 1983), and aircraft piloting (Mulgund, Asdigha, Zacharias, Krishnakumar, \& Dohme, 1995). Many researchers and practitioners have pointed out a gap between theoretical courses and professional practices. Therefore, they have implemented a variety of designed virtual settings to help the learner be able to gain deep understanding of complex concepts and to develop complex skills before going to practice in real situations. For example, Jazz Corner (www.jazzcorner.com) is a website that provides an opportunity for jazz musicians to continue their professional development (King, 2001). Luengo and associates (Luengo, Mufti-Alchawafa, and Vadcard 2007; Chieu, Luengo, Vadcard, and Tonetti, in press) have created a simulation-based intelligent learning environment, as an intermediate phase of learning, to help the novice surgeon master pragmatic knowledge in the domain of orthopedic surgery. Mulgund, Asdigha, Zacharias, Krishnakumar, and Dohme (1995) have developed a simulation-based intelligent flight trainer to help novice pilots develop skills on rotary wing maneuvers.

For both preservice and in-service mathematics teachers, learning to improve the practice of teaching is an important goal (Lampert, 2010; Shavelson, 1983). Teaching, however, is extremely complex (Leinhardt \& Ohlsson, 1990): teachers confront highly 
Running head: EMBEDDED ANIMATIONS AND ONLINE DISCUSSION. Accepted for publication at the Journal of the Learning Sciences

variable situations from moment to moment and from class to class. For this reason the design of technologies to help teachers learn to do the practice of teaching requires more than the technologies used to help students master academic subjects. Building successful virtual settings for teacher development—such as online experiences, courses, and communities of practice (Wenger, 1998) - may require a wide range of advanced technologies as well as research methods drawn from different disciplines.

Various technologies have been used to support teacher learning (Fishman \& Davis, 2006). One common technology is the use of video records of classroom instruction, which have been useful to bring to the fore the tactical-temporal entailments of practice (Lampert \& Ball, 1998). Indeed, video records may help teachers learn about, for example, subject matter or pedagogical knowledge (Wang \& Hartley, 2003), pedagogical content knowledge (Lampert \& Ball, 1998), and noticing (van Es \& Sherin, 2008). Online communities may also help teachers exchange ideas about their practice. For example, LabNet (Ruopp, Gal, Drayton, \& Pfister, 1993) used text-based e-mail and bulletin boards to build a community of practice among secondary science teachers. PBS Mathline project (Rockman et al., 1996) attempted to reduce teacher isolation through formal online course offerings. Math Forum (Renninger \& Shumar, 2004) built a community for students, hobbyists, and math educators to access high quality materials, activities, and person-to-person interactions.

A critical problem of the use of video records of instruction in real classrooms has been that they may direct too much attention to idiosyncratic characteristics of individuals or of the setting (Herbst \& Chazan, 2006; Herbst, Chazan, Chen, Chieu, and Weiss, in press). When video artifacts are shared in an online community, another 
Running head: EMBEDDED ANIMATIONS AND ONLINE DISCUSSION. Accepted for publication at the Journal of the Learning Sciences

problem has been the lack of technologies to enable student teachers to pinpoint specificities of the embedded artifacts (e.g., an event occurring at a particular time code in the video), and annotate, share, and discuss those specificities with others. Rather, the usual mode of interaction is to watch a whole video clip, and then annotate and discuss the clip in its entirety.

Our research aims to seek a number of operational principles that help design web-based interactive rich-media virtual settings for teachers to learn (or improve) the practice of teaching. We apply design-based research (Brown, 1992; Collins, 1992) in which we use different methods to perform a series of studies. This iterative and selfcorrecting process provides an optimal path toward the implementation of complex richmedia learning environments (Rieber, 2005). In this article, we report on the first study of that process. The study was designed to partly address the above two problems. We concentrate on the following two critical technologies used to stimulate teachers' discussion about their professional knowledge: (1) the use of animated classroom stories, and (2) the use of online interactive chat/forum in which an animation artifact is embedded directly in the virtual space of chat/forum and the participants have full control over the playback of the embedded animation. Animations of stylized cartoon characters can eliminate those elements too particular to individuals or settings which are often present in video records (e.g., students' body mass or teacher's age), while still preserving those elements relevant to the core of classroom interaction (e.g., students' conversations), and thus help viewers focus on critical moves of the teacher and students (Herbst \& Chazan, 2006). Particularly, because they allow teachers to project features of their own settings (such as their own students) onto the characters in the screen, they also 
Running head: EMBEDDED ANIMATIONS AND ONLINE DISCUSSION. Accepted for publication at the Journal of the Learning Sciences

invite practitioners to propose alternatives of the animated teacher's actions. Furthermore, we contend that allowing the participants to directly access specific moments of the shared animation embedded in chat/forum, as a common reference point, could provide significant help in stimulating them to share and discuss specificities of their professional practice such as teaching tactics.

Becoming a successful professional in mathematics teaching requires that teachers be able to notice critical events of classroom interaction, and to evaluate and interpret those events in new ways (Ball \& Cohen, 1999). van Es and Sherin (2008) refer to this as "professional vision for reform teaching." It is important to create opportunities, such as designed virtual settings described previously, so that teachers can share and discuss what they notice, and evaluate and interpret features of their teaching practice (Connelly, Clandinin, \& He, 1997; van Es \& Sherin, 2002). In this study, we concentrate on analyzing what the teachers notice while watching the teaching practice represented in an animation that is embedded in online forum/chat and how they evaluate and interpret what they notice. We compare the ability to notice and interpret significant aspects of instructional practice between a group of preservice teachers and a group of in-service teachers, and between two groups of participants using forum and chat; and we investigate the associations between, for example, when users refer to the embedded animation and how they notice and interpret the teacher and students' moves. We emphasize the ability to notice and interpret important aspects of teaching practice, such as teaching tactics and students' thinking, because teachers (especially novice teachers) may notice features that are not relevant or critical to the practice of their profession, or may not know how to interpret what they notice. 
Running head: EMBEDDED ANIMATIONS AND ONLINE DISCUSSION. Accepted for publication at the Journal of the Learning Sciences

\section{Theoretical Framework and Technologies for Supporting Teacher Learning}

Fishman and Davis (2006) have identified a number of critical problems to engage teachers in learning (or improving) the practice of teaching. Firstly, in-service teachers are typically isolated from one another in their work, which may prevent them from learning productively from each other in a social context (Lortie, 1975). Secondly, preservice teachers get insufficient opportunities to learn about the practice of teaching in situated and authentic contexts, such as observing experienced teachers' classrooms in action (Fishman \& Duffy, 1992) and practicing teaching tactics or techniques in a real classroom. Thirdly, both preservice and in-service teachers get insufficient support for the use of a variety of valuable resources in their pursuit of learning to do the work of teaching, for example, knowledge of the subject to be taught, knowledge of pedagogy, pedagogical content knowledge (Shulman, 1986), and knowledge about students' conceptions (Crespo, 2000; Franke \& Kazemi, 2001).

In this section, we narrow our review to the use of online communities of practice for sustaining teacher learning, and in particular to the use of video technologies to support teachers' learning to notice important aspects of teaching practice. Interested readers may examine the work of Fishman and Davis (2006) and the work of Barab, Kling, and Gray (2004) for more extensive reviews of teacher learning research.

\section{Online Communities of Practice for Teacher Learning}

The notion of communities of practice, deliberately examined by Wenger (1998) in a situated learning theory, designates "groups of people who share a concern, a set of problems, or a passion about a topic, and they deepen their knowledge and expertise in 
Running head: EMBEDDED ANIMATIONS AND ONLINE DISCUSSION. Accepted for publication at the Journal of the Learning Sciences

this area by interacting on an ongoing basis." (Wenger, McDermott, \& Snyder, 2002, p. 4). What makes communities of practice different from other communities is their basic structure, a unique combination of three fundamental elements: a domain of knowledge, a community of participants, and a shared practice. The domain defines a set of common interests that stimulate members of the community to contribute and participate, it guides their learning, and it makes their actions meaningful. The community creates a social context of learning in which every member is encouraged to actively express personal points of view, ask critical questions, comment on others' ideas, and so forth; in other words, it helps fostering interactions and relationships based on mutual respect and trust. The practice is the collection of specific artifacts and knowledge that members of the community produce and share, based on the basic knowledge of the community that every member is expected to have mastered. Through creating and sharing new artifacts and knowledge in the community, members can learn productively from each other. The previous three characteristics may be necessary but not always sufficient to build successful learning environments. For example, sometimes one may need to create specific conditions that truly stimulate and facilitate every participant to actively express personal perspectives on the practice that members of the community are sharing and discussing (see how we support this point in the next section about the design of our virtual settings).

A club of friends who meet each other every week to talk about anything they want may not be considered as a community of practice because they do not define a specific domain of interest to which they have commitments. By contrast, a video club of teachers (van Es \& Sherin, 2008) can be considered as a community of practice because it 
Running head: EMBEDDED ANIMATIONS AND ONLINE DISCUSSION. Accepted for publication at the Journal of the Learning Sciences

creates a social context for a group of in-service teachers (i.e., community) to develop and share specific artifacts (e.g., video clips of their own teaching) of their practice and transact knowledge about how to notice and interpret critical features of classroom interactions (i.e., domain). They may actually learn from each other how to notice and interpret important aspects of their professional practice.

Many online communities of practice have been created to mitigate teachers' usual isolation and to support productive collaboration. The core technologies of those communities are typically online communications tools such as email, bulletin or discussion boards, and live chats, which support open exchange of ideas among participants. One of the largest online communities of practice for professional development is Tapped In (Farooq, Schank, Harris, Fusco, \& Schlager, 2008; Schlager \& Fusco, 2004), a virtual environment that is based on a sociotechnical infrastructure. Tapped In is intended to sustain online activities of a large and diverse community of education professionals, including teachers. Tapped In also provides a variety of authoring tools allowing others to create their own online communities of practice. For instance, Pepperdine University used the Tapped In platform to sustain online graduate programs in educational technology (Riel \& Polin, 2004). A number of studies (e.g., Farooq, Schank, Harris, Fusco, \& Schlager, 2008) indicate that Tapped In has been successful in bringing together and forging reliable relationships among teachers and researchers around the world on a daily basis.

Whereas Tapped In is a domain-independent platform, the Math Forum (Renninger \& Shumar, 2004) is a highly successful, interactive, and inquiry-informed digital library for mathematics education. Teachers who join the Math Forum can discuss 
Running head: EMBEDDED ANIMATIONS AND ONLINE DISCUSSION. Accepted for publication at the Journal of the Learning Sciences

issues, share ideas, and ask questions with peers in a growing and active community. The Math Forum has used the Tapped In platform to build a Q\&A virtual space where both teachers and students can meet with "Dr. Math." It has also archived the best interactions from site services such as the "Problem of the Week" which teachers can use as a source for non-routine challenge problems in their teaching. The Math Forum has built its community of practice for teachers by combining face-to-face workshops and online activities. It helps teachers become leaders in the community and allows them to contribute resources and professional expertise. Renninger and Shumar (2002) suggest that the community provides teachers with an experience that is different from their other learning experiences and with many opportunities to learn to do and teach mathematics.

The Inquiry Learning Forum (ILF) is another virtual community of practice (Barab, Makinster, \& Scheckler, 2004). It has been used to support both preservice and in-service teachers in mathematics and science in sharing, improving, and creating inquiry-based, pedagogical practices. What makes ILF unique is that the development of the community has been grounded in design-based research (Brown, 1992; Collins, 1992). The first part of the iterative research process suggests the following four critical design principles: (a) foster ownership and participation so that teachers are responsible for building and maintaining their own environment, (b) foster pedagogy inquiry in the classroom and inquiry into teachers' own practices, (c) situate teachers in the social context of other members' teaching practice through the use of video streaming and webbased technologies, and (d) organize groups of teachers around collective experiences and/or curricular interests. The second part of the process provides further design implications for other online communities of practice. For example, designers should 
Running head: EMBEDDED ANIMATIONS AND ONLINE DISCUSSION. Accepted for publication at the Journal of the Learning Sciences

explicitly acknowledge the sociability issues they face, differentiate between face-to-face and online components of professional development, balance the predefined and emergent designs to meet the changing needs of the participants, and balance the local and immediate needs of teachers and the more global interests of designers.

The Secondary Teacher Education Project (STEP) is a technology-based distributed professional learning community for teacher education (Derry, Seymour, Steinkuehler, Lee, \& Siegel, 2004). The originality of STEP is that the implementation of the community has been grounded in a synthesis of four theoretical perspectives regarding the nature of social knowledge construction: (a) a sociocultural/situative viewpoint (Greeno, 1998; Wertsch, 1991), (b) a sociocognitive viewpoint (e.g., DuRussel \& Derry, 1998), (c) an argumentation perspective (e.g., Halpern, 1996; Kuhn, 1991), and (d) a group information processing theory (Hinsz, Tindale, \& Vollrath, 1997; Smith, 1994). Although at the time that the authors of STEP documented its implementation, cooperating teachers had not yet been real members of a knowledge building community, STEP was at a critical intermediate stage to attain that objective, as the teachers played important roles such as science authority, synthesizer, questioner, collaborator and questioner, and peripheral member in the structure the authors had designed. The study also indicates the difficulty of balancing the design goals of creating a spontaneously interacting and self-sustaining community and the users' need of a platform for facilitating the construction of ideas. This finding is consistent with the study of the ILF platform.

A common feature of the previous platforms has been the use of traditional communication tools such as forum and chat. In the following section, we show how 
Running head: EMBEDDED ANIMATIONS AND ONLINE DISCUSSION. Accepted for publication at the Journal of the Learning Sciences

users' virtual discussion space can be improved with the use of embedded video technologies.

\section{Video Technologies for Learning to Notice}

Noticing and interpreting important features of professional practice are critical skills in many professions (Goodwin, 1994). Research on those skills has a long history. DeGroot (1965) showed that expert chess players were able to notice and interpret more noteworthy patterns than novice players, and that expert players used those patterns to make decisions that were better than those of novice players. Studies of teacher expertise have reported similar findings (Furlong \& Maynard, 1995; Sabers, Cushing, \& Berliner, 1991). For example, Sabers, Cushing, and Berliner (1991) used video technologies to investigate the differences among expert, beginning, and novice teachers. They asked teachers to watch three video records, each focusing on a group of students working in a junior high science class, and to notice and respond to questions about classroom management and interaction. They found differences among the three groups of teachers in perception, noticing, and understanding of classroom events, which are characterized by simultaneity (i.e., many events occurred at the same time), multidimensionality (i.e., a large number of diverse events and tasks in classrooms), and immediacy (i.e., the fast pace of classroom events). More specifically, experienced teachers are able to notice, understand, and interpret classroom events in more detail and with more insight than either beginning teachers or novice teachers; and hence expert teachers frequently make more appropriate decisions than do the other two groups of teachers. 
Running head: EMBEDDED ANIMATIONS AND ONLINE DISCUSSION. Accepted for publication at the Journal of the Learning Sciences

van Es and Sherin (2008) suggest, however, that although experienced teachers may already have the ability to notice and interpret significant features of teaching practice, they may need to develop the skill of noticing and interpreting further in the context of mathematics education reform (NCTM, 2000). Indeed, a number of studies indicate positive values for teachers to learn to examine classroom interactions in new ways in the context of reform (e.g., Ball \& Cohen, 1999; Rodgers, 2002). One example of such “new ways" is van Es and Sherin's (2002) "Learning to Notice Framework." According to this framework, the skill of noticing for teaching practice consists of three main aspects: (a) determining what is significant in a teaching situation, (b) using what the teacher knows about the context of teaching to reason about the situation, and (c) making connections between specificities of noticed events and broader principles of teaching and learning.

The previous three characteristics are grounded in a significant number of earlier studies about noticing in different professions (e.g., Goodwin, 1994), including teaching. Researchers (e.g., Leinhardt, Putnam, Stein, \& Baxter, 1991) suggest that expert teachers use the ability to identify critical features during instruction to assess the progress of classroom interaction and to make decisions to advance that interaction. Regarding the second aspect, research has shown that as teachers gain more experience in the use of knowledge of their local context and mathematical knowledge for teaching (Ball, Thames, \& Phelps, 2008; Hill, Blunk, Lewis, \& Ball, 2008) such as common knowledge of content, pedagogical content knowledge, and knowledge of students and content, they become more versed in making sense of teaching situations (Hill, Blunk, Lewis, \& Ball, 2008; Perkins \& Solomon, 1989). Regarding the third dimension, prior research (e.g., 
Running head: EMBEDDED ANIMATIONS AND ONLINE DISCUSSION. Accepted for publication at the Journal of the Learning Sciences

Hughes, Packard, \& Pearson, 2000; Copeland, Birmingham, DeMeulle, D'EmidioCaston, \& Natal, 1994) has found that experts in many professions, and expert teachers in particular, are versed in making connections between concepts and principles and specific situations.

Video technologies are very common in supporting teacher learning in general and noticing in particular. Video records of classroom interaction have helped teacher viewers examine the tactical-temporal entailments of practice. Many materials in teacher education have been created around the use of video records of practice (e.g., Boaler \& Humphreys, 2005; Seago, Mumme, \& Branca, 2004). Several video-based programs have been developed to foster mathematics teachers to learn to teach in new ways (Sherin, 2004; Wang \& Hartley, 2003). Lampert and Ball (1998) built Space for Learning and Teaching Exploration (SLATE), a hypermedia environment to support novice teachers in developing pedagogical content knowledge. SLATE contained an archive of student work, classroom tasks, teaching reflections, video of students working, and video of teaching episodes. What made SLATE unique was a rich and detailed corpus that recorded an entire year of teaching. The environment provided novice teachers with various situations to support the development of subject matter knowledge for teaching, and those situations were presented in a manner that helped the users see the complexity of real-life classroom interactions.

Star and Strickland (2008) used video-based class lessons to help preservice teachers in mathematics improve their ability to observe and interpret significant events of classroom practice. The use of video artifacts to support noticing was integrated in a 15-week methods course in which 28 teacher students were enrolled. Preassessment and 
Running head: EMBEDDED ANIMATIONS AND ONLINE DISCUSSION. Accepted for publication at the Journal of the Learning Sciences

postassessment of how students of teaching noticed features of video artifacts were used before and after the course (i.e., whether they attended to significant features of teaching practice). The study indicates that these novices' observation skills, particularly the ability to notice critical features of the classroom environment, of mathematical content, and of teacher and student interaction, increased significantly.

van Es and Sherin (2008) designed a video club to support in-service teachers in learning to notice and interpret students' mathematical thinking. In this club, seven fourth and fifth grade elementary teachers whose teaching experience ranged from one to over twenty years met ten times, one or two times each month throughout a school year. In each meeting, the participants shared two or three five-to-seven-minute video clips of their own teaching, and discussed, with the assistance of a facilitator, students' ideas about mathematics, evidence to support claims they made about students' thinking, interpretation of students' understanding about mathematics, and so forth. The study suggests that the teachers' analyses of video clips positively shifted in terms of who and what they found noteworthy, of how they analyzed those interactions, and of their level of specificity.

In the next section, we explain why we use animation artifacts to stimulate discussion among users.

\section{Beyond Traditional Video and Communication Technologies: Embedding Animations in Online Interactive Discussion}

While video records have been and continue to be useful means to support research in the learning sciences in general (Derry et al., 2010) and teacher learning in 
Running head: EMBEDDED ANIMATIONS AND ONLINE DISCUSSION. Accepted for publication at the Journal of the Learning Sciences

particular (Le Fevre, 2004), animations of cartoon characters present advantages in representing scenarios of instruction. Herbst, Chazan, Chen, Chieu, and Weiss (in press) have classified representations of teaching practice by using the dimensions of temporality (the extent to which the representation reproduces for the viewer the passing of time in classroom interactions) and individuality (the extent to which the representation reproduces for the viewer the deployment of individuality in characters and setting in classroom interaction). On those considerations, a written case has low temporality (in that events that took short time may be described in long swaths of text while long spans of time may be represented in one sentence) and low individuality (in that all characters and settings are symbolized with words rather than displayed the way they manifested in the events represented). Likewise an unedited video record of practice has high temporality since events take as long in the video as they took in the real events represented; and it has high individuality in that much of the individuality of characters and setting from the real event is reproduced in the video representation (but see Hall, 2000). The importance of those dimensions is that they enable consideration of alternatives that might capitalize on advantages of both representation systems. Animations of non-descript cartoon characters, such as those created by project ThEMaT (http://grip.umich.edu/themat; Herbst and Chazan, 2003) immerse the viewer in a temporality closer to that of real classroom action but offer an experience of individuality somewhere in between video and text since choices made in the representation of people do not keep track of singularities such as age, hairstyle, skin complexion, height, body mass, and the like; rather people are represented with icons which are rather like each other. These kind of animations of nondescript cartoon characters (and comic book print 
Running head: EMBEDDED ANIMATIONS AND ONLINE DISCUSSION. Accepted for publication at the Journal of the Learning Sciences

versions of them also developed by ThEMaT) may thus reproduce for the viewer the temporal and tactical demands of real classroom interaction while inviting viewers to project onto the scenarios the individualities of the settings where and the people with whom they practice (Chazan \& Herbst, in review). We have noted that this design feature may help overcome one key limitation of video records: That they can be too particular to invite inference for people who teach in settings too different from those where the video was recorded (Herbst \& Chazan, 2006) Although this kind of complexity reduction of classroom interactions may not be relevant for all experiences in teacher education, we believe that it can be useful to represent and thus support teachers' learning to notice and interpret important aspects of instructional practice. These elements include the subject of studies, students' conceptions, and the discourse medium in which one and the other are transacted (Cohen, in press).

Herbst, Nachlieli, and Chazan (in press) found evidence that the ThEMaT animations ${ }^{1}$ can represent instructional practices to the point that they elicit discussion among experienced teachers about actions and decisions in teaching, stimulating viewers to reveal often tacit elements of the rationality that guides their usual actions, arguably helping them develop a shared professional discourse (see also Herbst \& Chazan, 2003; Chazan, Sela, and Herbst, submitted). In face-to-face study groups, animated classroom stories have been effective both in sketching classroom scenarios that experienced teachers found compelling, and in helping to elicit normative aspects of their practice that are usually tacit. The animations have been critical in creating opportunities for teachers to share and discuss their common practical knowledge of their profession, and thus learn

\footnotetext{
${ }^{1}$ Interested readers may request an account at http://grip.umich.edu/themat/ to view examples of animated classroom stories.
} 
Running head: EMBEDDED ANIMATIONS AND ONLINE DISCUSSION. Accepted for publication at the Journal of the Learning Sciences

productively from each other about different alternatives to a given teaching situation or problem. Furthermore, teachers may feel more comfortable criticizing the actions of cartoon teachers (in animation artifacts) than criticizing the actions of human teachers (in video artifacts).

One of our research objectives is to determine and validate a set of operational design principles that can be used to optimally exploit interactive rich-media technologies in the implementation of virtual settings, such as online learning environments and online communities of practice, for supporting teachers' learning to notice and interpret important aspects of instructional practice. In the first phase of a design-based research, we study how animated representations of teaching can help teachers notice and discuss their professional knowledge.

In virtual settings, particularly in online communities of practice such as those described earlier, a communication space for participants to share and discuss their professional knowledge is important. Traditional text-based communication tools have been frequently used for that purpose. There have been, however, several critical problems with online discussion, for example, lack of focus on learning content (Collison, Elbaum, Haavind, \& Tinker, 2000), lack of meaningful interaction among learners (Larson \& Keiper, 2002), and lack of in-depth discussion (Gunawardena, Lowe, $\&$ Anderson, 1997). One of the main reasons for these problems is a lack of shared artifacts that need to be explicitly provided for participants in discussion space. Indeed, Neale, Carrol, and Rosson (2004) contend that lack of shared context as a reference point could be a critical cause of failure for online discussion in general. Wise, Padmanabhan, and Duffy (2009) argue that it is difficult for learners to discuss their experiences 
Running head: EMBEDDED ANIMATIONS AND ONLINE DISCUSSION. Accepted for publication at the Journal of the Learning Sciences

meaningfully if there is a lack of a shared practice as a point of reference that helps them understand each other better in the difficult context of text-based conversation. We also believe that shared artifacts that represent both common and specific professional knowledge are useful for fostering in-depth and meaningful interactions among a group of users about their professional interests. This is true not only for communities of practice in particular but also for any learning environment in general (Wenger, McDermott, \& Snyder, 2002; Wenger, 1998). So, the main and original feature of our virtual setting, which goes beyond traditional online communication tools, is the embedding of an animated classroom story, as a shared artifact, directly in the users' discussion space. For example, Figure 1 shows a forum in which an animated clip is embedded on the left hand side of the forum space.

The shared artifact is available to every participant in the group, but another critical question is how to support them in navigating the animation and pinpointing to specificities of the respective teaching practice. Video clips in both traditional and online discussion groups have been often used as "atomic" records: users view a clip from the beginning to the end of the clip, and then discuss the clip in its entirety. To enable users to discuss an animation in more detail, we propose that each user should have full control over the playback of the animation provided to him or her so that he or she can easily access and review specific moments or actions or events in the shared artifact in which he or she is interested. This may encourage him or her to invite others to discuss those specific features of practice. 
Running head: EMBEDDED ANIMATIONS AND ONLINE DISCUSSION. Accepted for publication at the Journal of the Learning Sciences

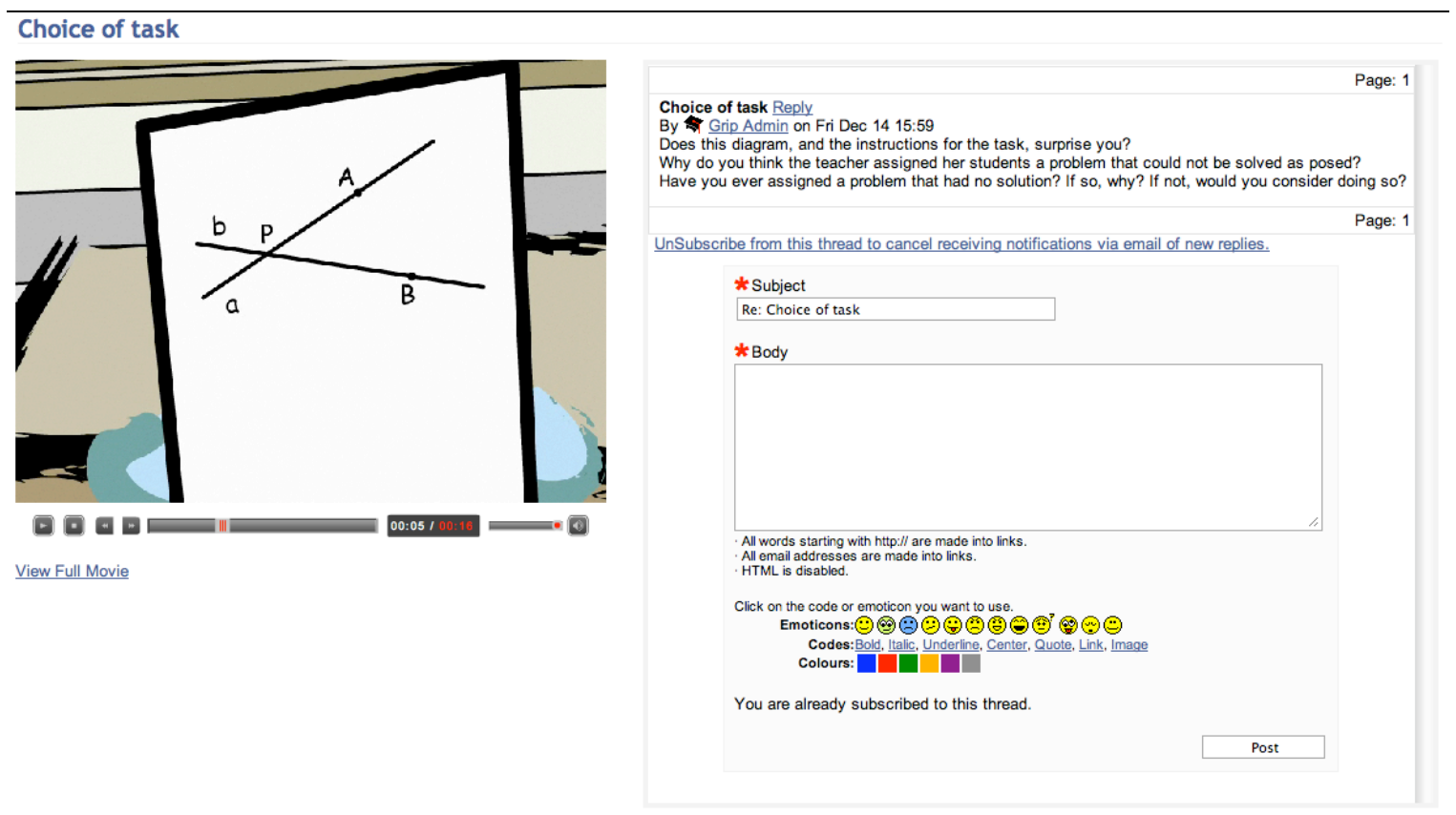

Figure 1. A web-based forum with an embedded clip.

Although the artifact and the tool are there for participants to use, they still may not (completely) know which features of the shared practice are critical to discuss. The role of the moderator or facilitator is therefore essential (Le Fevre, 2004). For instance, in the video club study (van Es \& Sherin, 2008) the role of the facilitator was not only to frame the discussion context but also to support teachers in learning to notice and interpret students' mathematical thinking. He or she thus prompted the participants to examine students' mathematical ideas, to give evidence they used to support their claims about students' thinking, and to interpret students' understanding about mathematics. In the study groups of ThEMaT, a moderator and a provocateur were used for each meeting (Nachlieli \& Herbst, 2010). The moderator's goal was principally to facilitate the session and to ask questions from the perspective of a teacher (e.g., What would you do in this case?). The provocateur's goal, in contrast, was to inquire into teachers' practical rationality from the viewpoint of a researcher (e.g., Why should a teacher do this or 
Running head: EMBEDDED ANIMATIONS AND ONLINE DISCUSSION. Accepted for publication at the Journal of the Learning Sciences

that?). In the context of online discussion, especially in live chat, we also argue that the role of the moderator is important. He or she can help better organize simultaneous threads of discussion, which can be a serious obstacle in online communication (Fuks, Pimentel, \& Pereira de Lucena, 2006). More importantly, he or she will be able to engage participants in sharing and discussing not only specific moments but also critical features of the shared practice they may miss, to elicit multiple perspectives or alternatives to the teacher's moves by participants, to give evidence on their comments, and so on (Le Fevre, 2004).

In this paper, we report on a study of a couple of online experiences designed to identify a number of operational design principles. By online experience we mean a structured exploration and discussion of an animated classroom story. Online experiences could be still far from reaching the notion of online communities of practice because of the nature of its short-term participation from users. We consider, however, that the study is an important step in a design-based research approach toward the design of more sustainable virtual settings. It may not provide a complete set of guidelines for the implementation of complex virtual settings such as online communities of practice, but it could provide several essential design principles for building those settings.

\section{Research Design}

\section{Research Questions and Method}

Designing interactive rich-media learning environments is obviously a complex

process. Thus, researchers (e.g., Farooq, Schank, Harris, Fusco, \& Schlager, 2007; Fuks, Pimentel, \& Pereira de Lucena, 2006; Rieber, 2005) have argued for the application of 
Running head: EMBEDDED ANIMATIONS AND ONLINE DISCUSSION. Accepted for publication at the Journal of the Learning Sciences

different research methods, for example from the paradigm of design-based research (Brown, 1992; Collins, 1992), to improve the effectiveness of the use of rich-media technologies. Design-based experiments couple the formative evaluation goal of successively improving an innovation's design by studying its use (by end users) with the combined scientific aims of theory building and theory testing (Collins, Joseph, \& Bielaczyc, 2004). Rieber (2005) notes that design-based research is especially relevant for studying advanced learning technologies:

A design experiment sets a specific pedagogical goal at the beginning and then seeks to determine the necessary organization, strategies, and technological support necessary to reach the goal $[\ldots]$ Such experiments involve an iterative and self-correcting process that resolves problems as they occur. The process is documented to show what path was taken to achieve the goal, what problems were encountered, and how they were handled. (p. 559)

Thus, the key difference between design-based research and traditional experimental research has been that design experiments offer the ability for a researcher or a group of researchers to show the evolution of an innovation's design, implementation, and use, rather than just concentrate on the results that come at the end of the design cycle. Participatory design, for example, is a particular kind of design-based research and has been largely used in the research of interactions between end users and innovative technologies (Fuks, Pimentel, \& Pereira de Lucena, 2006; Kensing \& Blomberg, 1998). The main point of participatory design is to involve end users as feedback participants in the design and development process of a product. Therefore, 
Running head: EMBEDDED ANIMATIONS AND ONLINE DISCUSSION. Accepted for publication at the Journal of the Learning Sciences

participatory design could be an effective means for the research and development of the type of virtual settings described earlier.

We followed the paradigm of design-based research to study the usability, usefulness, and effectiveness of the online experiences described in detail in the next subsection. By usability, we mean how easy it is for teachers to use the tools provided in the online experiences (e.g., how easy it is for users to post a message in a forum); by usefulness, how the provided tools support teachers' discussion (e.g., whether participants watch the embedded animation and whether they use it to make discussion more in-depth and meaningful); and by effectiveness, whether the provided tools have an effect on what teachers notice and how they interpret what they notice. Particularly, we wish to understand whether the interactive discussion and the embedded clips help teachers notice and interpret specific and significant matters in the classroom story, such as mathematical ideas, students' mathematics, and the teacher's tactics and planning.

More specifically, for effectiveness we particularly attend to the following three questions: (1) How does the nature of the online discussion tools (chat vs. forum) affect teachers' ability to notice and interpret important aspects of their professional practice? (2) What are the differences between in-service and preservice teachers' ability to notice and interpret aspects that are relevant and critical to teaching practice in the two online conditions? And (3) what are the correlations among variables that gauge teachers' ability to notice and interpret critical events of instructional practice and those that gauge how they refer to the embedded clips - for example, the correlation between when they attend to specific moves of the animated teacher or students, and whether they notice and interpret teaching tactics, or whether their comments are specific? 
Running head: EMBEDDED ANIMATIONS AND ONLINE DISCUSSION. Accepted for publication at the Journal of the Learning Sciences

\section{Online Experiences}

Table 1 shows the two online experiences. In each online experience, teachers participated in a series of consecutive activities: the participants in the forum condition did activity (1) and then activity (2); the participants in the chat condition did activity (1), then activity (3), and finally activity (4). Warm-up activities, see (1) and (3), were designed to facilitate interactive communication in the forms of an asynchronous forum and a live chat.

\section{Table 1. Two online experiences.}

\section{Forum condition}

\section{Chat condition}

(1) What comes in between? The individual teacher views a clip from the beginning of a lesson and a clip from the end of the lesson. Then, they are asked to respond to questions about what might happen in between. Finally, they view the full story, and are invited to comment on their answers.
(2) Forum: Three discussion threads are provided in
(3) Discussion of specific moments: The individual
advance. Each thread corresponds to a noteworthy
teacher views three clips representing three
moment of the story. In each thread, a clip
noteworthy moments of the story, and responds to
representing the moment is embedded and several
a few questions related to each moment (the same
questions are presented. Teachers collectively moments and questions used in the forum threads).
respond to questions and discuss moments. A
(4) Chat: Teachers and a moderator use a text-
moderator is present in the forum. Participants can
based chat to discuss the story. The animated story
view the embedded clip and the whole story with full
is embedded so that participants can view the story
control at any time. They can add other discussion
with full control at any time (see also Figure 1).
threads.
The moderator guides the participants to focus on discussing the three specific moments.


Running head: EMBEDDED ANIMATIONS AND ONLINE DISCUSSION. Accepted for publication at the Journal of the Learning Sciences

The animated classroom story (The Tangent $\mathrm{Circle}^{2}$ ) is about the teaching of the theorem "a circle exists which is tangent to two intersecting lines at two given points if and only if the two given points are equidistant from the intersection." In the story, the teaching of that theorem is accomplished through involving students in a construction problem: To draw a circle tangent to two given, intersecting lines, at two given points of tangency. As posed, the problem is unsolvable because the points are ostensibly not equidistant from the intersection of the two lines. In the story, various "solutions" to the problem are proposed and debated. Ultimately the class comes to the conclusion that the two points of tangency need to be equidistant from the intersection point, a conclusion that the teacher then restates as a theorem. The first noteworthy moment of the story mentioned in both experiences is about the teacher's choice of task. The second moment is about the teacher's interpretation of a specific student's mathematical idea (Lambda states that it is only possible to draw a circle which is tangent to both lines at two given points if the points can be moved a little bit). The third moment is about the teacher's management of students' interaction around that mathematical idea (the class objects to Lambda's proposal, and the teacher allows their criticism to continue unchecked for quite some time).

\section{Participants and Procedure}

Nine in-service mathematics teachers, each with more than three years of experience teaching geometry, constituted the in-service teachers sample. They came from diverse school settings (four from urban schools, two from suburban schools, two

\footnotetext{
${ }^{2}$ The animation can be viewed in http://grip.umich.edu/themat.
} 
Running head: EMBEDDED ANIMATIONS AND ONLINE DISCUSSION. Accepted for publication at the Journal of the Learning Sciences

from rural schools, and one from a private school) and included three men and six women. They were randomly assigned to two virtual groups: four in the forum experience and five in the chat experience (Table 1). Each participant used a laptop to explore his or her online experience during two hours while located in separate rooms of the same campus. By "explore", we mean to view animation clips, respond to questions related to the clips, and share and discuss practical knowledge of teaching while watching the embedded clips in forum or the full animation in chat. After having explored the online experience, all participants in the same virtual group gathered together in the same physical space to talk with researchers about their experience. We asked questions about the usability, usefulness, and effectiveness of the online experience in which they took part; because they had all participated previously in ThEMaT's face-to-face study groups, and were thus familiar with the ThEMaT animations, the questions and comments focused on the experiences of viewing and discussing the materials online.

The same online experiences were offered to eight preservice mathematics teachers, four in each online experience. Those preservice teachers had also previously seen ThEMaT's animations and discussed them in a teacher education class.

\section{Data Sources and Data Analysis}

Data included screen records of interaction between the participants and the online experiences, session logs, and video records of focus groups after the online experiences. For usability evaluation evidence, we examined participants' individual comments at the end of the online experience and collective comments in focus groups. For usefulness evaluation evidence, we calculated, among other things, the number of 
Running head: EMBEDDED ANIMATIONS AND ONLINE DISCUSSION. Accepted for publication at the Journal of the Learning Sciences

sentences each participant contributed in forum/chat to estimate how actively they participated, the number of times they viewed the embedded animation and duration of each view to estimate how often they used it during discussion, and the "depth" of discussion topics to estimate the interactivity level of discussion (we explain how to calculate that below). For effectiveness evaluation, forum and chat logs were coded to understand what and how teachers noticed during discussion. The Appendix shows a 5category coding scheme, which is partly based on a coding system used by van Es and Sherin (2008) in the video club study described previously. For Topic codes, we consider that all of the content topics (mathematics, students' mathematics, teachers' tactics, teachers' planning, and emotion and climate) are critical for teachers to notice. The other topics are not significant but we have classified them to facilitate the coding process. Although we have not associated a significance level to Subject codes, we want to know how often teachers talk about their own professional practice and how consistent the topic noticed and the subject noticed are (e.g., whether teachers attend to the students when they notice students' mathematics). For Stance codes, evaluating and especially interpreting the practice are more critical than merely describing it. For Specificity codes, making specific comments is usually better than making general comments. Finally, we have chosen Temporality codes to understand the effect of the embedded animation on what teachers notice, for example, to find the correlation between making specific comments and referring to the embedded animation. The choice of the codes presented in the Appendix is justified more in the next section about results and discussion.

A chat line may contain multiple sentences, each of which may in principle respond to different chat lines; therefore a chat line may refer to different topics. Hence, 
Running head: EMBEDDED ANIMATIONS AND ONLINE DISCUSSION. Accepted for publication at the Journal of the Learning Sciences

we have adopted the sentence as our unit of analysis. A chat line may contain one or several analysis units and an analysis unit sometimes is a combination of two or more chat lines (e.g., when the speaker divides a single sentence into multiple chat entries). Similarly, a forum message usually contains many sentences. The choice of the sentence as the analysis unit has been used in several qualitative analyses of online discussion, and it could improve the reliability of the analysis process in comparison with the choice of the paragraph or theme as the unit of analysis (Rourke, Anderson, Garrison, \& Archer, 2001). To break chat and forum logs into sentences, we rely on how the participants organized their written text into sentences (e.g., a sentence is usually started with a capital letter and terminated with a period or exclamation mark or question mark).

Although the analysis unit is the sentence, we performed the data analysis by considering the context in which the sentence is involved. In the chat condition, however, there are often multiple discussion threads at the same time and it is thus difficult to know who the addressee of a sentence is (e.g., a comment such as "I agree" may be directed at any number of prior posts). In the forum condition, sometimes the user may mistakenly reply to a "seed" entry though he or she wants to reply to a subentry of that "seed" entry, probably because he or she is not familiar with the use of the online forum. In this case, it is also difficult to know to whom he or she is replying. Therefore, we applied a discourse analysis method (Schiffrin, Tannen, \& Hamilton, 2003) to detect cohesion and themes in the chat and forum logs. We created a cohesion diagram for each chat/forum log. That is a simple tree-structured graph that shows which units reply to which units and by whom. We coded units of "seed" forum messages or chat lines to be 0 while units replying to a 
Running head: EMBEDDED ANIMATIONS AND ONLINE DISCUSSION. Accepted for publication at the Journal of the Learning Sciences

unit coded $n$ were coded $n+1$. The interactivity level of each theme/log was the average of the codes of all units of that theme/log.

The choice of the sentence as the analysis unit can help improve the blindness of the analysis process. Indeed, we applied the following process to make the analysis as blind as possible: Each chat/forum log was broken into sentences. Each sentence was associated with a unique ID number and the login name of the participant who wrote the sentence. The moderator's contribution was included but not analyzed. The same login name ("moderator") was used for the moderator in both forum and chat. Each login name was labeled with a different color. A cohesion diagram was built for each chat/forum log by using the ID numbers and the assigned colors. Finally, sentences were coded according to the previous coding scheme. This process could help ensure that the analyst did not know which condition (chat/forum) and which kind of participants (preservice/inservice teachers) he or she was analyzing. It is, however, difficult to make the analysis completely blind. For example, it is usual that sentences in forum are longer than those in chat.

In assigning the codes, for each coding category we gave one code to each analysis unit. We coded categories independently. In addition, coding was not inherited by replies, meaning that if a unit was coded as time code precision for Temporality, then units that replied to that unit were not automatically coded as time code precision. When the Topic was coded with one of the "context topics" (media, user-interface, and interpersonal) or with other, we did not assign any code to the other categories.

To check the reliability of the coding system, two coders (also the first and third authors of this article) independently coded about $28 \%$ analysis units of a chat $\log$ and 
Running head: EMBEDDED ANIMATIONS AND ONLINE DISCUSSION. Accepted for publication at the Journal of the Learning Sciences

compared the two analysis results. We found a $94 \%$ interrater agreement on the unitization (the total number of units made by the two coders divided into twice the number of units upon which they agreed). We found interrater agreements of $95 \%, 95 \%$, $91 \%, 95 \%$, and $91 \%$ for the result of the analysis using the five coding categories described above. We calculated the coefficient of reliability by dividing the number of coding decisions upon which the two coders agreed by the number of coding decisions made by each coder (both coders made the same number of coding decisions from the set of units used). We also calculated Cohen's kappa (k) statistic to assess the reliability (Cohen, 1960), and the kappa values of $.88, .83, .69, .83$, and .67 were obtained for the aforementioned five coding categories. Regarding kappa values, Capozzoli, McSweeney, and Sinha (1999) indicate that:

values greater than 0.75 or so may be taken to represent excellent agreement beyond chance, values below 0.40 or so may be taken to represent poor agreement beyond chance, and values between 0.40 and 0.75 may be taken to represent fair to good agreement beyond chance. (p. 6)

Because the observations (i.e., sentences) are not independent, when making comparisons we aggregated sentences for each participant and used participants' total number of codes as scores (participants may not be independent either but we believe that the level of dependency of participants is much lower than that of sentences). For example, if a participant wrote 80 sentences that were specific and 20 sentences that were not specific, the scores for this participant were 80 for the specific code (each specific sentence contributed 1 to the total score even if the sentence was coded with multiple levels of specificity) and 20 for the general code in the Specificity category. 
Running head: EMBEDDED ANIMATIONS AND ONLINE DISCUSSION. Accepted for publication at the Journal of the Learning Sciences

We used a generalized logistic mixed model (with chi-square tests) and Stata software to examine the covariation among different variables across the five categories described earlier, for example, whether their comments were more specific when they made reference to the embedded animation than when they did not, whether they discussed more teachers' tactics when they referred to events or actions of the animation than when they did not. Those results are useful for us to have better understanding of the complete effect of the embedded animation.

\section{Results and Discussion}

\section{Usability}

Almost all participants were impressed with the online experience they explored and found the interactive discussions easy to participate in. Here is a preservice teacher's comment on the forum condition:

I really enjoyed this session. I think that the forums are a wonderful way to have teachers interact and share ideas in a timely manner. The forums were really easy to use.

Two in-service teachers had difficulties keeping up with the speed of communication in the chat condition, some of which they attributed to slow typing, some to switches of discussion happening concomitantly with their writing of an entry. Those findings are consistent with others' (e.g., Fuks, Pimentel, \& Pereira de Lucena, 2006). Here is an experienced teacher's comment on the chat condition:

This was really hard for me. I didn't feel as if there was a single conversation. The pure time lag between questions and answers made things 
Running head: EMBEDDED ANIMATIONS AND ONLINE DISCUSSION. Accepted for publication at the Journal of the Learning Sciences

more confusing. Sometimes I would find myself in the middle of an answer and then have to erase it because the conversation had taken a different turn. It seemed like when [the moderator] starting [sic] organizing us more, the work became more logical.

The principle here is to consider participants' technology skill in the design of chat tools. We may need to improve traditional chat tools (e.g., better organizing simultaneous discussion threads) or to encourage participants with little technology experience to use asynchronous forum instead of live chat.

\section{Usefulness}

All participants, except for one in-service teacher in chat, actively participated in interactive discussion. Indeed, they contributed a significant number of sentences during discussion. Furthermore, in the forum condition experienced teachers created three additional discussion threads (all of them were related to the animation and two of them attracted a number of responses). Prospective teachers created two additional threads; one was related to teaching methods presented in their classes, and attracted a significant number of responses, and the other was related to user-interface issues. Those factors could indicate the usefulness of the forum condition, in the sense that it stimulated participants to discuss issues about the animation or teaching practice not anticipated.

Figure 2 shows interactivity levels of identified themes and chat/forum logs. The participants in both conditions primarily focused on the discussion of the embedded animation. In other words, they spent very little time on off-track topics such as welcome, user interface, and wrap-up. So, the embedded clips, as shared artifacts of professional 
Running head: EMBEDDED ANIMATIONS AND ONLINE DISCUSSION. Accepted for publication at the Journal of the Learning Sciences

practice, seem to have been useful in stimulating meaningful discussions. Our analysis of screen records also supported that claim. All participants in forum viewed the whole embedded clip (if available) at least one time in each discussion thread they joined. All participants in chat viewed different segments (from several seconds to several minutes) of the embedded animation several times during discussion; sometimes they looked for specific moments using the scrubber of the video player, sometimes they watched the animation while typing.

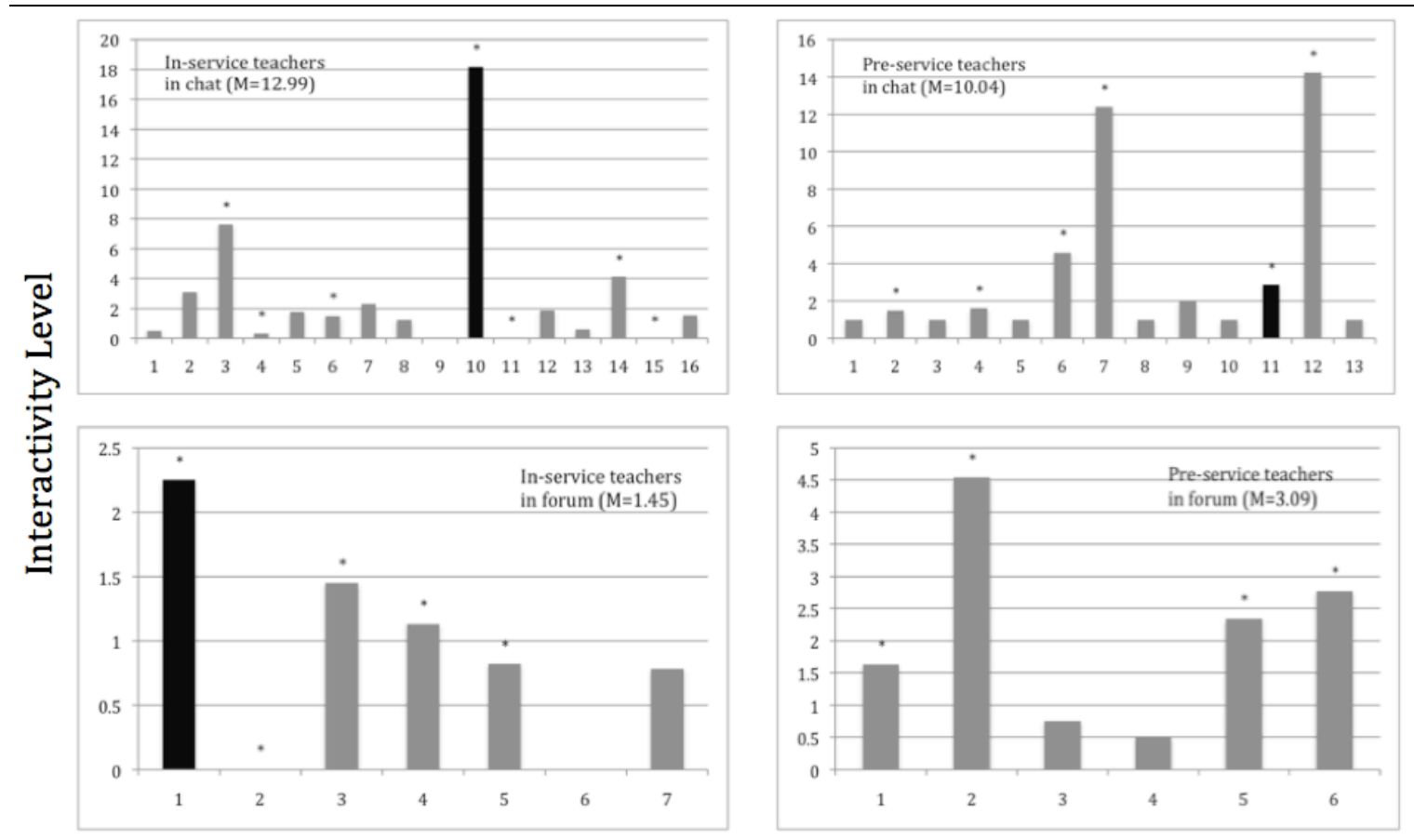

Theme ID

Figure 2. Interactivity levels of discussion themes ${ }^{3}$.

\footnotetext{
${ }^{3}$ Bars with a star symbol on the top represent "content themes" and bars without that symbol represent "context themes"; black bars indicate themes in which users referred to time code of the embedded animation; themes are sorted in an ascendant order by time at which they were raised and presented from left to right in each chart.
} 
Running head: EMBEDDED ANIMATIONS AND ONLINE DISCUSSION. Accepted for publication at the Journal of the Learning Sciences

Furthermore, when they all focused on specific moments (i.e., references to time code precision), the discussion was much deeper (see Figure 2) and meaningful (all discussion threads in which they referred to time code were about noticing critical aspects of instructional practice). For example, an experienced teacher in the chat room initiated a discussion thread and asked others to look at a specific moment, and subsequently made reference to another time code; this became the most prominent and meaningful discussion thread of the chat. In the chat room of preservice teachers, although thread 11 (Figure 2), initiated when a participant invited others to examine a noteworthy event, did not evoke a high level of interactivity, it nevertheless played an important role in stimulating the following thread, which was highly prominent in the chat. The role of the moderator in helping the participants deepen those discussions was crucial. Indeed, he kept asking them to choose and discuss critical events, and when they did, he kept encouraging them to propose alternatives and to comment on those alternatives.

The following is a preservice teacher's positive comment on the embedded clips in the forum:

I enjoyed the session. [...] I also liked that we could play the clip from what the forum topic was about. It was very helpful.

And here is another encouraging comment of an experienced teacher about the embedded animation in the chat:

[...] I really like being able to look at a specific spot in the film without making everyone else look at the same spot. In the [face-to-face] sessions I was often not interested in the same spot of video that others were. 
Running head: EMBEDDED ANIMATIONS AND ONLINE DISCUSSION. Accepted for publication at the Journal of the Learning Sciences

The first design principle here is to embed rich-media content, as shared artifacts of professional practice, into forum/chat. The second design principle is to allow the participants to have full control of the embedded artifacts, providing each individual his or her own control tool, for example, the scrubber of the video player — on the grounds that the more specifically the users can pinpoint a moment in the embedded artifacts, the deeper their discussion can be. Finally, the third design principle is that the moderator should be present, especially in chat, and he or she should help not only organize concurrence discussion threads, but also stimulate the participants to look at noteworthy actions or events or contents, to suggest alternatives, and to give comments on alternatives.

\section{Effectiveness}

Figure 3 shows the result of the analysis of what the teachers noticed, whom they were talking about, the stance they took toward what they noticed, the specificity level of their comments, and how they made reference to the embedded clips. The numbers in the charts indicate the percentages of the total number of analysis units for each group.

Overall, the teachers in all groups focused on discussing practical knowledge of their profession (more than $70 \%$ of their sentences were about content, see the analysis results of Content Topic and Context Topic in Figure 3). More specifically, the participants narrowed the focus on referring to students' mathematics, teachers' tactics and planning, and students' emotion and classroom climate. They predominantly paid attention to the animated teacher and/or students, and often took evaluative and/or interpretive stances. Except for the prospective teachers in the chat condition, the 
Running head: EMBEDDED ANIMATIONS AND ONLINE DISCUSSION. Accepted for publication at the Journal of the Learning Sciences

participants' comments were specific, and the specificity was frequently about pedagogy. The in-service teachers frequently made reference to the animation when they made comments. Those results were comparable with those of the video club study (van Es \& Sherin, 2008) previously cited.

Topics. The analysis of Content Topic (Figure 3) indicates that in-service teachers in forum referred more to teachers' planning than did in-service teachers in chat $(\mathrm{p}<.05)$, a result that also was found for prospective teachers $(\mathrm{p}<.005)$. The main reason for those differences may lie in the difference of organizational characteristics between chat and forum: in principle, forum is more structured than chat. Indeed, in the forum condition we provided the participants with initial discussion threads in advance, all of which were directly or indirectly related to teachers' planning. Discussion in chat, on the other hand, can go more freely and spontaneously than that in forum. Even when the moderator in the chat condition asked the teachers the same questions used in the forum condition, they may have easily missed those questions and attended to other topics instead because of the highly interactive and multi-threaded nature of chat. 
Running head: EMBEDDED ANIMATIONS AND ONLINE DISCUSSION. Accepted for publication at the Journal of the Learning Sciences
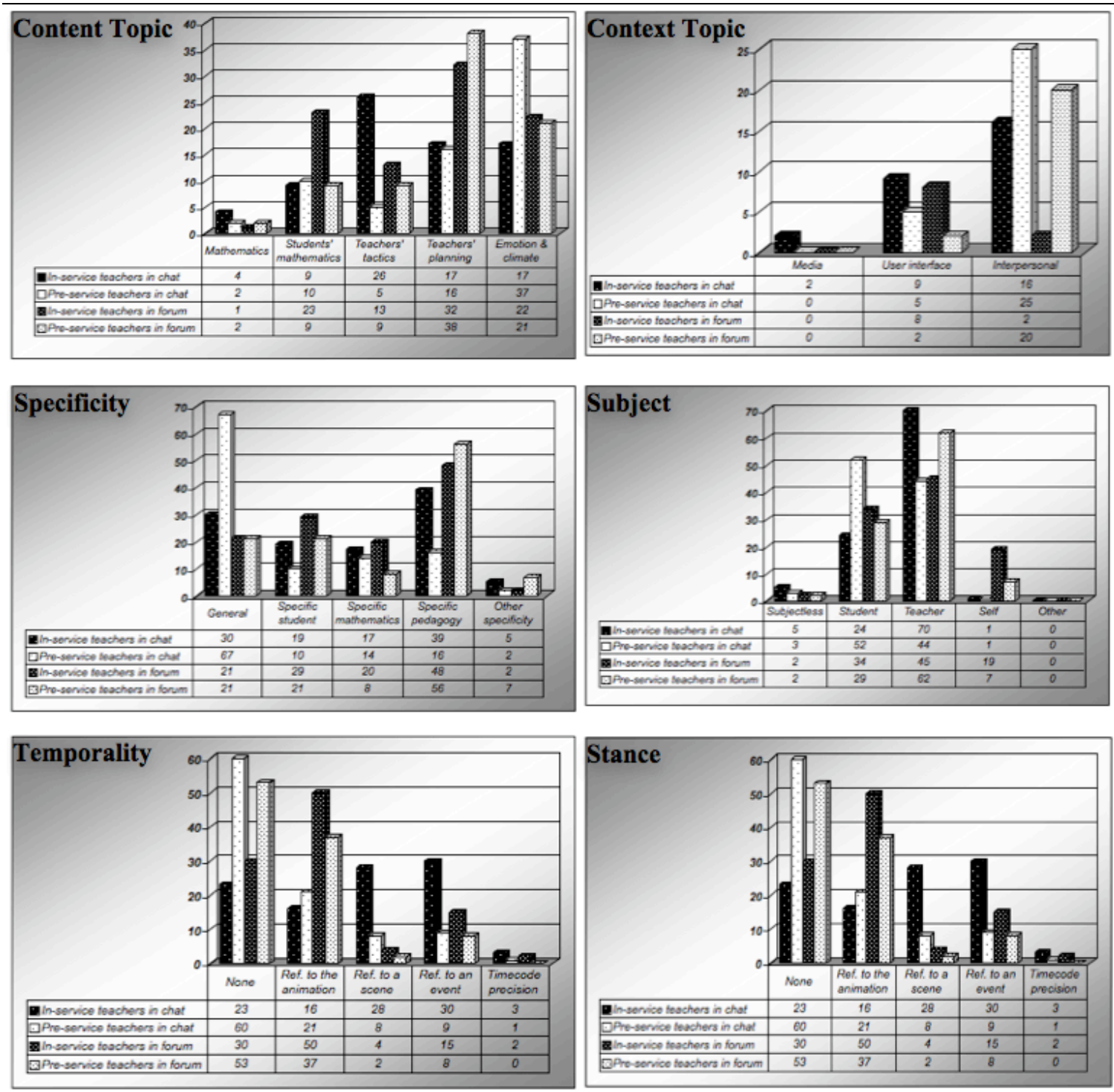

Figure 3. Analysis results of participants' noticing.

In the chat discussions, experienced teachers commented more on teachers' tactics than did experienced teachers in forum or preservice teachers in chat. The differences were highly significant $(\mathrm{p}<.005)$. The differences between preservice teachers' comments and those of in-service teachers in the same forum condition and between preservice teachers' in chat and those in forum were not significant. Hence, it seems that in a more open discussion space, in-service teachers were more likely to discuss teaching 
Running head: EMBEDDED ANIMATIONS AND ONLINE DISCUSSION. Accepted for publication at the Journal of the Learning Sciences

tactics, and they had the capacity to manage that kind of complex discussion well, which we speculate may have been because they had experience in managing classroom interaction (Berliner et al., 1988 suggest that teachers' ability to notice is positively related to teachers' classroom experience). In-service teachers in the forum condition did not discuss teachers' tactics too much, possibly because they were given three predefined threads to discuss other topics.

Preservice teachers in the chat condition attended more to students' emotion and classroom climate. The differences between this group's noticing and other groups' with regard to that topic were significant $(\mathrm{p}<.05)$. Star and Strickland (2008) identify as a problem that novice teachers tend to attend little to important topics such as students' actions and thinking if the group discussion is not well organized and guided (Berliner et al., 1988).

The previous results may suggest a design principle that both chat and forum can be useful to support experienced teachers' noticing and discussion whereas only forum can be suitable for novice teachers. Indeed, chat and forum stimulate practicing teachers' discussion in different ways, and thus they can be complementary to each other. The forum condition, which is better organized and guided and less interactive than the chat condition (even with the assistance of the moderator), may help novice teachers balance their analytic focus (i.e., not attending too much to students' emotion and classroom climate and too little to teachers' tactics and planning and students' mathematics).

Subjects. The analysis of Subject (Figure 3) suggests that preservice teachers in chat attended more to the students and less to the teacher than did both in-service teachers in the same condition and preservice teachers in forum $(\mathrm{p}<.005)$. This seems to be 
Running head: EMBEDDED ANIMATIONS AND ONLINE DISCUSSION. Accepted for publication at the Journal of the Learning Sciences

consistent with the previous result that prospective teachers in chat attended more to student emotion and climate than did practicing teachers in chat and prospective teachers in forum.

Experienced teachers in forum referred more to self than did those in chat and novice teachers in forum $(\mathrm{p}<.05)$. This means that in-service teachers were likely to benefit from the less interactive nature of forum to talk more about their own professional practice (i.e., they would have had more opportunity to connect their comments with their own teaching experience). Those results may consolidate the design principle noted in the previous sub-section.

Stance. Both preservice and in-service teachers in both chat and forum mainly adopted an evaluative or interpretive stance (more than $75 \%$, see the analysis result of Stance in Figure 3). Among seven evaluative dimensions, their comments were more about desirability/inclination or warrantability/probability than about other dimensions. The difference was highly significant $(\mathrm{p}<.01)$. It means that they frequently proposed alternatives to the teaching decisions that the animated teacher had made.

The novice teachers in chat adopted an interpretive stance less than did the other three groups, and the differences were very significant $(\mathrm{p}<0.005)$. The evidence could indicate that online discussion tools (chat or forum) do not affect how often in-service teachers form interpretations. Forum, however, could be more relevant than chat for preservice teachers in terms of fostering them to form interpretations, because in a slower and more organized interaction mode (forum vs. chat) they are likely to have more time and reflection to interpret what they notice. Those results also strengthen the previous design principle about the use of chat and forum for novice and experienced teachers. 
Running head: EMBEDDED ANIMATIONS AND ONLINE DISCUSSION. Accepted for publication at the Journal of the Learning Sciences

Specificity. The analysis result of Specificity (Figure 3) shows that more than two thirds of the comments of the practicing teachers in both chat and forum and of the prospective teachers in forum were specific, whereas only about one third of the comments of the prospective teachers in chat were specific, and the differences were extremely significant $(p<.005)$. In those three groups, when the participants made specific comments, they talked much more about specific pedagogy than about specific mathematics or a specific student; that is, they frequently gave details about what the teacher would, should, or could do. The novice teachers in the chat condition seemed to have difficulties managing highly interactive discussion and tended to make general comments: they may not have had enough time for reflection and for thinking about details of their ideas. In other words, we speculate that the well-organized structure of forum and/or the experience in managing classroom interactions seemed to help the other three groups of teachers make more specific comments.

Again, novice teachers may find forum easier for them to specify what they notice, but there seems to be no difference between chat and forum for experienced teachers.

Temporality. When making comments in both forum and chat, experienced teachers referred more to the embedded animation clips than did the novice teachers, and the differences were significant $(\mathrm{p}<.01$, see also the analysis result of Temporality in Figure 3). Those differences between experienced teachers or between novice teachers in the two conditions, however, were not significant.

Once more, it seems that in a complex environment such as online rich-media discussion, in-service teachers use resources around them better than preservice teachers 
Running head: EMBEDDED ANIMATIONS AND ONLINE DISCUSSION. Accepted for publication at the Journal of the Learning Sciences

do, possibly because in-service teachers have more experience in managing complex classroom interaction: they know when to use which resources and why and how those resources could be useful to attain their objectives (Lin, Schwartz, \& Hatano, 2005; Westerman, 1991).

Covariations. The usefulness result described earlier indicates that when the teachers referred to the embedded animation their discussion was more in-depth and meaningful than when they did not. Particularly, the interactivity level was much higher when they made reference to an event or action or when they specified a time code in the animation than when they did not. Our following analysis of covariations may strengthen that point further.

The analysis of covariations suggests that a relationship existed between referring to the embedded animation clips in general and making specific comments; this relationship did not vary across groups of teachers. Overall, in any group of participants, the probability of being specific for sentences that did not refer to the animation clips was just $60 \%$ of the probability of being specific for sentences referring to the animation clips $(95 \% \mathrm{CI}=[.24, .97], \mathrm{p}=.001)$

The analysis also indicates that referring to a scene or an event or a time code of the embedded animation clips and making specific comments were related to each other, but that relationship varied across groups of teachers. For example, in the group of experienced teachers in chat, the probability that a sentence that did not refer to a scene or an event or a time code of the animation would be specific was $72 \%$ of the probability that a sentence referring to a scene or an event or a time code of the animation would be specific $(95 \% \mathrm{CI}=[-1.36,-.08], \mathrm{p}=.028)$. 
Running head: EMBEDDED ANIMATIONS AND ONLINE DISCUSSION. Accepted for publication at the Journal of the Learning Sciences

The previous findings suggest that participants' comments were more specific when they referred to the embedded animation than when they did not. The existence of that relationship may provide evidence for the effectiveness of the embedded animation clips. Indeed, if one assumes that making specific comments can engage participants in more in-depth and meaningful discussions and help them notice important events of teaching practice better (which might affect how well they learn how to teach better), then it is useful to encourage them to make reference to the specificities of the shared artifacts when they make comments. Embedding shared artifacts directly in the virtual space of discussion is an effective design principle to sustain this specificity.

Another significant relationship between discussing teaching tactics and making specific comments was found, and that covariation did not vary across groups of participants. The probability that a sentence that did not refer to teaching tactics would be specific was $57 \%$ of the probability of being specific for tactic sentences $(95 \% \mathrm{CI}=[-$ $1.05,-.09], \mathrm{p}=.021)$. This finding is not surprising but it strengthens the design principle that encouraging participants (e.g., by the moderator) to talk about teaching tactics in their discussion is important and useful (for them to make specific comments).

\section{Conclusions}

In this paper, we report on a study of a design-based research agenda whose longterm goal is to research, design, and develop web-based interactive rich-media environments for both prospective and practicing teachers to learn to teach. The core technologies we use include animations of classroom stories and advanced communication technologies in which shared artifacts are embedded directly to 
Running head: EMBEDDED ANIMATIONS AND ONLINE DISCUSSION. Accepted for publication at the Journal of the Learning Sciences

discussion space. The study provides a set of relatively operational design principles (Table 2). This set is obviously not definitive: more work in the next cycles of the designbased research process is needed to consolidate those principles as well as to propose and validate new principles.

Regarding Principle 1 in Table 2, although the use of shared artifacts in face-toface conversation to stimulate meaningful discussion is not new, it is relatively new in the context of web-based communication, especially if the shared artifacts are in the forms of rich media such as videos or animations. About ten years ago, it was almost impossible to embed rich-media artifacts directly in a virtual communication space because of limited Internet bandwidth. Recently, however, that limitation has no longer been a problem for many end users at home as well as at the workplace, making it much easier to implement this design principle.

We believe that the nature of embedded artifacts may affect the nature of discussion (i.e., noticing and interpreting critical aspects of instructional practice), as we previously conjectured that animations would be better than, or at least as good as, videos for supporting teachers' learning to notice and interpret important events of their professional practice. This study shows that the embedded animation clips can be comparable with video clips used in the video club study (van Es \& Sherin, 2008) in supporting teachers' development of noticing ability. We shall conduct more studies to better understand the difference of the effectiveness between the two kinds of representations, for example, to compare the noticing ability of two groups of experienced teachers engaging in two different chat rooms: one embedded with an 
Running head: EMBEDDED ANIMATIONS AND ONLINE DISCUSSION. Accepted for publication at the Journal of the Learning Sciences

animation and the other embedded with a video (both the animation and the video represent the same classroom story).

Both video and animation technologies can be useful not only for supporting teacher learning but also for creating assessment tools for research on teacher expertise such as teacher thinking and decision-making (Herbst \& Chazan, 2003). For example, Mestre and Feil (in press) have suggested a method using video technologies as follows: The researcher can show a video segment of teaching practice to a teacher or a group of teachers and ask them to take notes, while they watch the video clip, on significant aspects of the practice that they would like to comment on or discuss later; then, immediately afterward the researcher can ask them to do the same task again but with a few changes of critical aspects of practice such as pedagogy and content to monitor what they notice over the two situations. As mentioned earlier, animations can provide effective representations of instructional practice with which to invite discussion among experienced teachers, eliciting the practical rationality that guides their usual actions (Herbst, Nachlieli, \& Chazan, in press). The point is that animation technologies may help challenge norms of usual teaching practice easily, stimulating teachers to talk about what might be possible to do in their own practice more frequently. Again, representations of teaching in the form of animations of cartoon characters could be more useful than video records of teaching, for example in executing the method suggested by Mestre and Feil (in press), to make changes of instructional practice straightforwardly.

For Principle 2 and Principle 3, although animation clips were embedded next to the discussion space, preservice teachers had full control over the playback of those clips, and the moderator frequently asked them to watch the clips and to seek and share critical 
Running head: EMBEDDED ANIMATIONS AND ONLINE DISCUSSION. Accepted for publication at the Journal of the Learning Sciences

events, they still did not seem to connect the shared artifact with their comments proficiently —at least not as proficiently as did in-service teachers. For this reason, we plan improvements to communication tools with respect to that issue. For instance, when a user composes a new entry or replies to an existing entry in forum, along with the title and the body of the new entry we will encourage the user to optionally input some sort of connection between his or her comment with the embedded clip. We may use automatically generated prompts such as "Which event(s) of the embedded clip could be most closely related to your current comment?"

Table 2.Design principles for web-based interactive rich-media settings.

Principle 1 Embed rich-media artifacts, as reference points, directly in the virtual discussion space to stimulate in-depth and meaningful discussion among the participants

Principle 2 Allow each user to have his or her own full control on the embedded artifacts so that he or she can pinpoint specificities of those artifacts, share those specificities with others, and ask others to discuss those specificities

Principle 3 Involve one or more moderators in forum or chat to help not only organize concurrent discussion threads but also encourage the participants to attend to critical features of practice, to propose alternatives, to comment on alternatives, to talk about tactics, and so forth

\footnotetext{
Principle 4 Consider the users' technology experience when assigning chat and forum conditions: forum may be more suitable than chat for users with less experience in using technology
}

Principle 5 Consider the users' teaching experience when assigning chat and forum 
Running head: EMBEDDED ANIMATIONS AND ONLINE DISCUSSION. Accepted for publication at the Journal of the Learning Sciences

conditions: both chat and forum can be complementarily good for experienced teachers whereas only forum may be relevant for novice teachers

We also plan to find the means to help participants better connect between discussing a topic and making specific comments. For example, we may present the moderators with a list of auxiliary questions embedded directly in their moderation space so that they can easily foster that relationship among participants. Here are a couple of examples: "Could you specify when and how you used/would use the tactic you just mentioned?" and "How did/would your students respond to the tactic you just mentioned?"

Finally, regarding Principle 4 and Principle 5, we found that in the forum condition novice teachers were able to attend to and discuss instructional practice in a manner that was closer to the way experienced teachers did. Sometimes, however, we also found that both preservice and in-service teachers in forum mistakenly replied to a "seed" entry though they wanted to reply to a sub-entry of that "seed" entry, probably because they had little experience in the use of online forum. This finding suggests the need to implement a new user interface for forum, in which participants' entries will be organized into a semantic and tree-structured format rather than in a chronological format that has been very common in many web-based forums. We implemented that feature in a new forum tool in the second iteration of our development process. Our preliminary observations with the use of the new forum tool by pre-service teachers indicate that the new forum format seems to resolve the above confusing issue and also help the learner of teaching follow discussion stories more easily. We plan to perform further analysis in the 
Running head: EMBEDDED ANIMATIONS AND ONLINE DISCUSSION. Accepted for publication at the Journal of the Learning Sciences

second iteration of the design-based research process to better understand the usability, usefulness, and effectiveness of the new forum tool.

\section{Acknowledgments}

The work reported in this paper is supported by NSF grant ESI-0353285 to Patricio Herbst. Opinions expressed here are the sole responsibility of the authors and do not necessarily reflect the views of the Foundation.

\section{Endnotes}

Parts of the paper were presented at AERA, San Diego, 2009, at SITE, Charleston, SC, 2009, and at ICLS, Chicago, 2010.

\section{References}

Ball, D. L., \& Cohen, D. K. (1999). Developing practice, developing practitioners:

Toward a practice-based theory of professional education. In G. Sykes \& L. DarlingHammond (Eds.), Teaching as the learning profession: Handbook of policy and practice (pp. 3-32). San Francisco, CA: Jossey Bass.

Ball, D. L., Thames, M., \& Phelps, G. (2008). Content knowledge for teaching: What makes it special? Journal of Teacher Education, 59(5), 389-407.

Barab, S., Kling, R., \& Gray, J. (2004). Designing for virtual communities in the service of learning. Cambridge, MA: Cambridge University Press.

Barab, S., MaKinster, J., \& Scheckler, R. (2004). Designing system dualities:

Characterizing online community. In S. Barab, R. Kling, \& J. Gray (Eds.), Designing 
Running head: EMBEDDED ANIMATIONS AND ONLINE DISCUSSION. Accepted for publication at the Journal of the Learning Sciences

for virtual communities in the service of learning (pp. 53-90). Cambridge, MA:

Cambridge University Press.

Berliner, D. C., Stein, P., Sabers, D. S., Clarridge, P. B., Cushing, K. S., \& Pinnegar, S. (1988). Implications of research on pedagogical expertise and experience in mathematics teaching. In D. A. Grouws \& T. J. Cooney (Eds.), Perspectives on research on effective mathematics teaching (pp. 67-95). Reston, VA: National Council of Teachers of Mathematics.

Boaler, J., \& Humphreys, C. (2005). Connecting mathematical ideas: Middle school video cases to support teaching and learning. Portsmouth, NH: Heinemann.

Bren, T. (2005). Transcultural competence in health care practice: The development of shared resources for practitioners. Practice, 17(4), 257-266.

Brown, A.L. (1992). Design experiments: Theoretical and methodological challenges in creating complex interventions. Journal of the Learning Sciences, 2, 141-178.

Capozzoli, M., McSweeney, L., \& Sinha, D. (1999). Beyond kappa: A review of interrater agreement measures. The Canadian Journal of Statistics, 27(1), 3-23.

Chazan, D. and Herbst, P. (re-submitted). Animations of classroom interaction: Expanding the boundaries of video records of practice. In review at Teachers' College Record.

Chazan, D., Sela, H., and Herbst, P. (submitted). Changes in the doing of word problems in school mathematics. In review at Cognition and Instruction.

Chieu, V.M., Vadcard, L., Luengo, V., \& Tonetti, J. (in press). Student modeling in complex domains: Exploiting symbiosis between temporal Bayesian networks and fine-grained didactical analysis. Journal of Artificial Intelligence in Education. 
Running head: EMBEDDED ANIMATIONS AND ONLINE DISCUSSION. Accepted for publication at the Journal of the Learning Sciences

Cohen, D. K. (forthcoming). Teaching: Practice and its predicaments. Harvard University Press.

Cohen. J. (1960). A coefficient of agreement for nominal scales. Educational and Psychological Measurement, 20, 37-46.

Collins, A. (1992). Toward a design science of education. In E. Scanlon \& T. O’Shea (Eds.), New directions in educational technology (pp. 15-22). Berlin, Germany: Springer-Verlag.

Collins, A., Joseph, D., \& Bielaczyc, K. (2004). Design research: Theoretical and methodological issues. Journal of the Learning Sciences, 13(1), 15-42.

Collison, G., Elbaum, B., Haavind, S., \& Tinker, R. (2000). Facilitating online learning: Effective strategies for moderators. Madison, WI: Atwood Publishing.

Connelly, F. M., Clandinin, D. J., \& He, M. F. (1997). Teachers' personal practical knowledge in the professional knowledge landscape. Teaching and Teacher Education, 13(7), 665-674.

Copeland, W. D., Birmingham, C., DeMeulle, L., D’Emidio-Caston, M., \& Natal, D. (1994). Making meaning in classrooms: An investigation of cognitive processes in aspiring teachers, experienced teachers, and their peers. American Educational Research Journal, 31(1), 166-196.

Crespo, S. (2000). Seeing more than right and wrong answers: Prospective teachers' interpretations of students' mathematical work. Journal of Mathematics Teacher Education, 3(2), 155-181.

DeGroot, A. D. (1965). Thought and choice in chess. The Hague, the Netherlands: Mouton. 
Running head: EMBEDDED ANIMATIONS AND ONLINE DISCUSSION. Accepted for publication at the Journal of the Learning Sciences

Derry, S. J., Pea, R. D., Barron, B., Engle, R. A., Erickson, F., Goldman, R., Hall, R., Koschmann, T., Lemke, J. L., Sherin, M. G., \& Sherin, B. L. (2010). Conducting video research in the learning sciences: Guidance on selection, analysis, technology, and ethics. Journal of the Learning Sciences, 19(1), 3-53.

Derry, S. J., Seymour, J., Steinkuehler, C., Lee, J., \& Siegel, M. (2004). From ambitious vision to partially satisfying reality: An evolving socio-technical design supporting community and collaborative learning in teacher education. In S. A. Barab, R. Kling, \& J. Gray (Eds.), Designing for virtual communities in the service of learning (pp. 256-295). Cambridge, MA: Cambridge University Press.

DuRussel, L., \& Derry, S.J. (1998, May). Mental models in educational research teams. Poster presented at the Annual Meeting of AERA, San Diego, CA.

Farooq, U., Schank, P., Harris, A., Fusco, J., \& Schlager, M. (2007). Sustaining a community computing infrastructure for online teacher professional development: A case study of designing Tapped In. Journal of Computer Supported Cooperative Work, 16(4-5), 397-429.

Fishman, B. J., \& Davis, E. A. (2006). Teacher learning research and the learning sciences. In R. Keith Sawyer (Ed.), The Cambridge handbook of the learning sciences (pp. 535-550). Cambridge, MA: Cambridge University Press.

Fishman, B. L., \& Duffy, T. M. (1992). Classroom restructuring: What do teachers really need? Educational Technology Research and Development, 40(3), 95-111.

Franke, M. L., \& Kazemi, E. (2001). Learning to teach mathematics: Focus on student thinking. Theory into Practice, 40(2), 102-109.

Fuks, H., Pimentel, M., \& Pereira de Lucena, C. J. (2006). R-U-Typing-2-Me? Evolving 
Running head: EMBEDDED ANIMATIONS AND ONLINE DISCUSSION. Accepted for publication at the Journal of the Learning Sciences

a chat tool to increase understanding in learning activities. Journal of Computer Supported Collaborative Learning, 1(1), 117-142.

Furlong, J., \& Maynard, T. (1995). Mentoring student teachers: The growth of professional knowledge. London, the United Kingdom: Routledge.

Goodwin, C. (1994). Professional vision. American Anthropologist, 96(4), 606-633.

Greeno, J.G. (1998). The situativity of knowing, learning, and research. American Psychologist, 53(1), 5-26.

Gunawardena, C. N., Lowe, C. A., \& Anderson, T. (1997). Analysis of a global on-line debate and the development of an interaction analysis model for examining social construction of knowledge in computer conferencing. Journal of Educational Computing Research, 17(4), 397-431.

Halpern, D.F. (1996). Thought and knowledge (3rd ed.). Mahwah, NJ: Erlbaum.

Herbst, P., Chazan, D., Chen, C., Chieu, V.M., \& Weiss, M. (in press). Using comicsbased representations of teaching, and technology, to bring practice to teacher education courses. ZDM-The International Journal of Mathematics Education.

Herbst, P. and Chazan, D. (2006). Producing a Viable Story of Geometry Instruction: What Kind of Representation Calls Forth Teachers' Practical Rationality? In Alatorre, S., Cortina, J.L., Sáiz, M., and Méndez, A.(Eds) Proceedings of The 28th Annual Meeting of the North American Chapter of the International Group for the Psychology of Mathematics Education (Vol 2, 213-220). Mérida, México: Universidad Pedagógica Nacional.

Herbst, P., \& Chazan, D. (2003). Exploring the practical rationality of mathematics teaching through conversations about videotaped episodes. For the Learning of 
Running head: EMBEDDED ANIMATIONS AND ONLINE DISCUSSION. Accepted for publication at the Journal of the Learning Sciences

\section{Mathematics, 23(1), 2-14.}

Herbst, P., Nachlieli, T., and Chazan, D. (in press). Studying the practical rationality of mathematics teaching: What goes into "installing" a theorem in geometry? Cognition and Instruction.

Hill, H. C., Blunk, M. L., Lewis, J. M., \& Ball, D. L. (2008). Mathematical knowledge for teaching and the mathematical quality of instruction: An exploratory study. Cognition and Instruction, 26, 430-511.

Hinsz, V.B., Tindale, R.S., \& Vollrath, D.A. (1997). The emerging conceptualization of groups as information processors. Psychological Bulletin, 121, 43-64.

Hughes, J. E., Packard, B. W., \& Pearson, P. D. (2000). The role of hypermedia cases on preservice teachers' views of reading instruction. Action in Teacher Education, $22(2 \mathrm{~A}), 24-38$.

Kensing, F., \& Blomberg, J. (1998). Participatory design: Issues and concerns. Journal of Computer Supported Cooperative Work, 7, 167-184.

King, K.D. (2001). Conceptually-oriented mathematics teacher development:

Improvisation as a metaphor. For the Learning of Mathematics, 21(3), 9-15.

Kuhn, D. (1991). The skills of argument. Cambridge, MA: Cambridge University Press.

Lampert, M. (2001). Teaching problems and the problems of teaching. New Haven, CT: Yale University Press.

Lampert, M. (2010). Learning teaching in, from, and for practice: What do we mean? Journal of Teacher Education, 61(1-2), 21-34

Lampert, M., \& Ball, D. L. (1998). Teaching, multimedia, and mathematics: Investigations of real practice. New York, NY: Teachers' College Press. 
Running head: EMBEDDED ANIMATIONS AND ONLINE DISCUSSION. Accepted for publication at the Journal of the Learning Sciences

Larson, B.E., \& Keiper, T.A. (2002). Classroom discussion and threaded electronic discussion: Learning in two arenas. Contemporary Issues in Technology and Teacher Education, 2(1). Retrieved from http://www.citejournal.org/vol2/iss1/socialstudies/article1.cfm.

Le Fevre, D. M. (2004). Designing for teacher learning: Video-based curriculum design. In J. Brophy (Ed.), Using video in teacher education: Advances in research on teaching (Vol. 10, pp. 235-258). London, the United Kingdom: Elsevier.

Leinhardt, G., Putnam, R. T., Stein, M., \& Baxter, J. (1991). Where subject knowledge matters. In P. Peterson, E. Fennema, \& T. Carpenter (Eds.), Advances in research on teaching (pp. 87-113). Greenwich, CT: JAI Press Inc.

Leinhardt, G., \& Ohlsson, S. (1990). Tutorials on the structure of tutoring from teachers. Journal of Artificial Intelligence in Education, 2, 21-46.

Lemke, J.L. (1998). Resources for attitudinal meaning: Evaluative orientations in text semantics. Functions of Language, 5(1), 33-56.

Lin, X. D., Schwartz, D. L., \& Hatano, G. (2005). Towards teacher's adaptive metacognition. Educational Psychologist, 40, 245-256.

Lortie, D. C. (1975). Schoolteacher: A sociological study. Chicago, IL: University of Chicago.

Luengo, V., Mufti-Alchawafa, D., Vadcard, L. (2007). Design of adaptive surgery learning environment with bayesian network. Proceedings of the 2007 International Technology, Education and Development Conference (CD publication, ISBN: 97884-611-4517-1). Valencia, Spain: International Association of Technology, Education and Development. 
Running head: EMBEDDED ANIMATIONS AND ONLINE DISCUSSION. Accepted for publication at the Journal of the Learning Sciences

Mestre J., \& Feil, A. (in press). Change blindness as a means of studying expertise in physics. Journal of the Learning Sciences.

Mulgund, S.S., Asdigha, M., Zacharias, G.L., Krishnakumar, K., \& Dohme, J.A. (1995).

An intelligent tutoring system for simulator-based helicopter flight training. Proceedings of the 1995 AIAA Flight Simulation Technologies Conference (pp. 121129). Reston, VA: AIAA.

Nachlieli, T., \& Herbst, P. (2010). Facilitating encounters among teachers with representations of teaching: Two registers. Retrieved from Deep Blue at the University of Michigan, http://hdl.handle.net/2027.42/64852.

NCTM (2000). Principles and standards for school mathematics. Reston, VA: National Council of Teachers of Mathematics.

Neale, D. C., Carroll, J. M., \& Rosson, M. B. (2004). Evaluating computer-supported cooperative work: Models and frameworks. In J. Herbsleb \& G. Olson (Eds.), Proceedings of Computer Supported Cooperative Work 2004 (pp. 112-121). New York, NY: ACM Press.

Perkins, D. N., \& Solomon, G. (1989). Are cognitive skills context-bound? Educational Researcher, 18(1), 16-25.

Renninger, K. A., \& Shumar, W. (2004). The centrality of culture and community to participant learning at and with The Math Forum. In S. A. Barab, R. Kling, \& J. H. Gray (Eds.), Designing for virtual communities in the service of learning (pp. 181209). Cambridge, MA: Cambridge University Press.

Renninger, K.A. \& Shumar, W. (2002). Community building with and for teachers: The Math Forum as a resource for teacher professional development. In K.A. Renninger \& 
Running head: EMBEDDED ANIMATIONS AND ONLINE DISCUSSION. Accepted for publication at the Journal of the Learning Sciences

W. Shumar (Eds.), Building virtual communities: Learning and change in cyberspace (pp. 60-95). New York, NY: Cambridge University Press.

Rieber, L. P. (2005). Multimedia learning in games, simulations, and microworlds. In R. E. Mayer (Ed.), The Cambridge handbook of multimedia learning (pp. 549-567). New York, NY: Cambridge University Press.

Riel, M., \& Polin, L. (2004). Online learning communities: Common ground and critical differences in designing technical environments. In S. A. Barab, R. Kling, \& J. H. Gray (Eds.), Designing for virtual communities in the service of learning (pp. 16-50). Cambridge, MA: Cambridge University Press.

Rockman et al. (1996). Evaluation of PBS Mathline middle school mathematics project 1995-1996: The second year. San Francisco, CA: Rockman et al. Retrieved from http://rockman.com/projects/pbs/Mathline.pdf.

Rodgers, C. R. (2002). Seeing student learning: Teacher change and the role of reflection. Harvard Educational Review, 72(2), 230-253.

Rourke, L., Anderson, T., Garrison, R., \& Archer, W. (2001). Methodological issues in the content analysis of computer conference transcripts. Journal of Artificial Intelligence in Education, 12, 8-22.

Ruopp, R. R., Gal, S., Drayton, B., \& Pfister, M. (1993). LabNet: Toward a community of practice. Hillsdale, NJ: Lawrence Erlbaum Associates.

Sabers, D.S., Cushing, K.S., \& Berliner, D.C. (1991). Differences among teachers in a task characterized by simultaneity, multidimensionality, and immediacy. American Educational Research Journal, 28, 63-88.

Schiffrin, D., Tannen, D., \& Hamilton, E. (2003). The handbook of discourse analysis. 
Running head: EMBEDDED ANIMATIONS AND ONLINE DISCUSSION. Accepted for publication at the Journal of the Learning Sciences

Malden, MA: Wiley-Blackwell.

Seago, N., Mumme, J., \& Branca, N. (2004). Learning and teaching linear functions:

Video cases for mathematics professional development, 6-10. Portsmouth, NH: Heinemann.

Shavelson, R. (1983). Review of research on teachers' pedagogical judgments, plans, and decisions. The Elementary School Journal, 83, 392-413.

Sherin, M. G. (2004). New perspectives on the role of video in teacher education. In J. Brophy (Ed.), Using video in teacher education (pp. 1-28). Oxford, the United Kingdom: Elsevier.

Shulman, L. (1986). Just in case: Reflections on learning from experience. In J. A. Colbert, P. Desberg, \& K. Trimble (Eds.), The case for reflection: Contemporary approaches for using case methods (pp. 197-217). Boston, MA: Allyn \& Bacon. Smith, J. (1994). Collective intelligence in computer-based collaborations. Hillsdale, NJ: Erlbaum.

Star, J.R., \& Strickland, S.K. (2008). Learning to observe: Using video to improve preservice teachers' ability to notice. Journal of Mathematics Teacher Education, 11(2), 107-125.

van Es, E.A., \& Sherin, M.G. (2008). Mathematics teachers' "learning to notice" in the context of a video club. Teaching and Teacher Education, 24(2), 244-276.

van Es, E. A. \& Sherin, M. G. (2002). Learning to notice: Scaffolding new teachers' interpretations of classroom interactions. Journal of Technology and Teacher Education, 10, 571-596.

Wang, J., \& Hartley, K. (2003). Video technology as a support for teacher education 
Running head: EMBEDDED ANIMATIONS AND ONLINE DISCUSSION. Accepted for publication at the Journal of the Learning Sciences

reform. Journal of Technology and Teacher Education, 11(1), 105-138.

Wenger, E. (1998). Communities of practice: Learning, meaning, and identity. New York, NY: Cambridge University Press.

Wenger, E., McDermott, R., \& Snyder, W. M. (2002). Cultivating communities of practice: A guide to managing knowledge. Boston, MA: Harvard Business School Press.

Wertsch, J.V. (1991). Voices of mind: A sociocultural approach to mediated action. Cambridge, MA: Cambridge University Press.

Westerman, D.A. (1991). Expert and novice teacher decision making. Journal of Teacher Education, 42(4), 292-305.

Wise, A.F., Padmanabhan, P., \& Duffy, T.M. (2009, April). Connecting online learners with diverse local practices: The design of effective common reference points for conversation. Paper presented at the Annual Meeting of AERA, San Diego, CA. 
Running head: EMBEDDED ANIMATIONS AND ONLINE DISCUSSION. Accepted for publication at the Journal of the Learning Sciences

\section{Appendix. Coding system for effectiveness evaluation.}

\section{Code \\ Description \\ Example}

\begin{tabular}{|c|c|c|}
\hline \multicolumn{3}{|c|}{ Topic (what was being talked about) } \\
\hline Mathematics & $\begin{array}{l}\text { Discussion of mathematical content (disconnected from how it } \\
\text { would be taught or how students understand it). }\end{array}$ & $\begin{array}{l}\text { The points on the } \\
\text { bisector are equidistant } \\
\text { from the tangent lines. }\end{array}$ \\
\hline $\begin{array}{l}\text { Students' } \\
\text { mathematics }\end{array}$ & $\begin{array}{l}\text { How students understand or misunderstand mathematical ideas } \\
\text { or practices, not including comments about affect (emotion, } \\
\text { motivation, etc.) or general characterizations of individuals. }\end{array}$ & $\begin{array}{l}\text { At } 3: 30 \text { or so Lambda } \\
\text { clearly says she could do } \\
\text { it if she could move the } \\
\text { points. }\end{array}$ \\
\hline $\begin{array}{l}\text { Teachers' } \\
\text { tactics }\end{array}$ & $\begin{array}{l}\text { How a teacher did/could/should respond to timely events, not } \\
\text { including atemporal teacher decision-making (e.g., how the } \\
\text { teacher would plan a task or a lesson). }\end{array}$ & $\begin{array}{l}\text { I have no doubt that the } \\
\text { teacher wanted to put } \\
\text { point } L \text { in the wrong } \\
\text { place. }\end{array}$ \\
\hline $\begin{array}{l}\text { Teachers' } \\
\text { planning }\end{array}$ & $\begin{array}{l}\text { How a teacher could structure a task or a lesson, not including } \\
\text { decision-making on the fly. This would include strategic } \\
\text { decision-making. Anything that could have been planned in } \\
\text { advance, including anticipated contingencies (you will always } \\
\text { have a kid that does that and as soon as that happens you need } \\
\text { to...). }\end{array}$ & $\begin{array}{l}\text { If the teacher had } \\
\text { marked on the picture } \\
\text { that the distances were } \\
\text { different, would this be } \\
\text { even more deceiving } \\
\text { than the problem already } \\
\text { is? }\end{array}$ \\
\hline $\begin{array}{l}\text { Emotion \& } \\
\text { Climate }\end{array}$ & $\begin{array}{l}\text { All affect-related comments, whether about the students' } \\
\text { feelings or about how the teacher managed classroom } \\
\text { mechanics. Strategic and tactical decision-making is excluded } \\
\text { here because this is not subject specific. }\end{array}$ & $\begin{array}{l}\text { I think the teacher } \\
\text { elevated the level of } \\
\text { frustration! }\end{array}$ \\
\hline Media & Comments on the media. & $\begin{array}{l}\text { I find it difficult to keep } \\
\text { the students identified } \\
\text { by their names because } \\
\text { they all look alike. }\end{array}$ \\
\hline User & Comments on the user interface of the online experience. & Now I know how to \\
\hline
\end{tabular}


Running head: EMBEDDED ANIMATIONS AND ONLINE DISCUSSION. Accepted for publication at the Journal of the Learning Sciences

$\begin{array}{ll}\text { Interface } & \text { replay the video. }\end{array}$

\begin{tabular}{lll}
\hline Interpersonal & Comments about each other, including salutations. & I agree.
\end{tabular}

Other Anything else, to be specified.

\begin{tabular}{|c|c|c|}
\hline \multicolumn{3}{|c|}{ Subject Noticed (who was being talked about) } \\
\hline Subjectless & $\begin{array}{l}\text { No subject is mentioned (usually talk about mathematical } \\
\text { facts). }\end{array}$ & $\begin{array}{l}\text { The points on the } \\
\text { bisector are equidistant } \\
\text { from the tangent lines. }\end{array}$ \\
\hline Student & Talk about the students in the animation or other students. & $\begin{array}{l}\text { At 3:30 or so Lambda } \\
\text { clearly says she could do } \\
\text { it if she could move the } \\
\text { points. }\end{array}$ \\
\hline Teacher & Talk about the teacher in the animation or other teachers. & $\begin{array}{l}\text { I have no doubt that the } \\
\text { teacher wanted to put } \\
\text { point } \mathrm{L} \text { in the wrong } \\
\text { place. }\end{array}$ \\
\hline Self & Talk about self in the past or present experiences. & $\begin{array}{l}\text { This is exactly how I } \\
\text { introduced the theorem } \\
\text { on Friday. }\end{array}$ \\
\hline
\end{tabular}

Other To be specified.

Stance (how the participant analyzed teaching practice)

\begin{tabular}{lll}
\hline Describe & $\begin{array}{l}\text { Statements that recounted the events that occurred in the } \\
\text { animation, in a general classroom, or in one's classroom. }\end{array}$ & When the teacher called \\
& Alpha to the board. \\
\hline Evaluate & $\begin{array}{l}\text { There is some marker of appraisal along one of the seven } \\
\text { dimensions proposed by Lemke (1998): desirability/inclination, },\end{array}$ & $\begin{array}{l}\text { Lambda go up to the } \\
\text { board and redraw the }\end{array}$ \\
warrantability/probability, normativity/appropriateness, & $\begin{array}{l}\text { diagram her way, things } \\
\text { usuality/expectability, importance/significance, }\end{array}$ & $\begin{array}{l}\text { would have stayed } \\
\text { comprehensibility/obviousness, humorousness/seriousness. }\end{array}$ \\
Multiple evaluative dimensions may be used for the same & [probability].
\end{tabular}

analysis unit. Usually, the appraiser is self and the appraised is 
Running head: EMBEDDED ANIMATIONS AND ONLINE DISCUSSION. Accepted for publication at the Journal of the Learning Sciences

an action (or an action proposal) by the teacher or student or

mathematics.

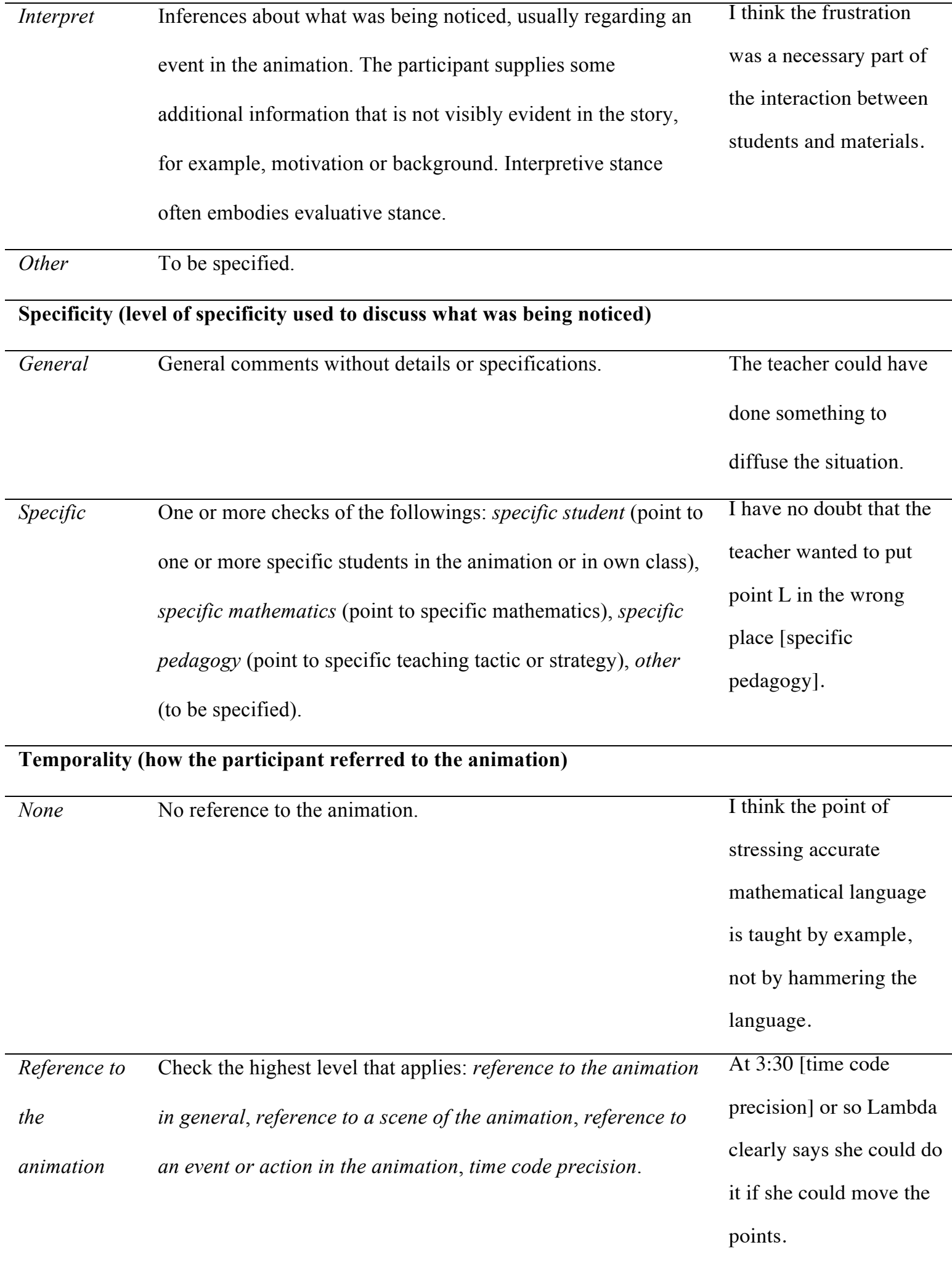


Running head: EMBEDDED ANIMATIONS AND ONLINE DISCUSSION. Accepted for publication at the Journal of the Learning Sciences 